DE

M E D I C I N A

T R O P I C A L

$\mathrm{DE}$

S ÃO PAULO

JOURNAL OF THE SÃO PAULO INSTITUTE OF TROPICAL MEDICINE

${ }^{1}$ Instituto de Infectologia Emílio Ribas, São Paulo, São Paulo, Brazil

2Universidade de São Paulo, Faculdade de Medicina, Laboratório de Investigação Médica em Neurologia (LIM 56), São Paulo, São Paulo, Brazil

${ }^{3}$ Universidade de São Paulo, Instituto de Medicina Tropical de São Paulo, São Paulo, São Paulo, Brazil

Correspondence to: Flávia Esper Dahy Instituto de Infectologia Emílio Ribas, Avenida Angélica, 2491, 9ำandar, CEP 01227-200, São Paulo, SP, Brazil Tel: +55 11 3230-0208

E-mail: neuro.flaviaesper@gmail.com

Jorge Casseb

Universidade de São Paulo, Instituto de Medicina Tropical de São Paulo,

Av. Dr. Enéas de Carvalho Aguiar, 500, Prédio II, 3o andar, CEP 05403-907,

São Paulo, SP, Brazil.

Tel: +55 $113061-7193$

Fax: $+55113081-7190$

E-mail: jcasseb @usp.br

Received: 2 March 2021

Accepted: 29 March 2021

\section{Small cells lung epidermoid carcinoma in a HTLV1-infected patient: case report and literature review}

Flávia Esper Dahy ${ }^{(1}$, Renata Basic Palhares ${ }^{1}$, Tatiane Assone ${ }^{2,3}$, Jerusa Smid'1, João Victor Luisi de Moura', Michel E. J. Haziot ${ }^{1}$, Rosa Maria N. Marcusso', Augusto César Penalva de Oliveira' ${ }^{1}$, Jorge Casseb ${ }^{\mathbb{2} 2,3}$

\section{ABSTRACT}

The human T cell lymphotropic virus type 1 (HTLV-1) is the first human retrovirus discovered. Since then, it has spread worldwide and is mainly associated with adult $\mathrm{T}$ cell leukemia/lymphoma (ATLL) and HTLV1-associated myelopathy (HAM). Its relationship, however, with other types of cancer is controversial. We describe the case of a patient presenting with small cells lung epidermoid carcinoma who had recently developed HAM, and a review of the literature related to these conditions. This is the first case of this type of lung cancer, the same of the first description in the literature, associated with HAM outside Japan.

KEYWORDS: HTLV-1. ATLL. Cancer. Neoplasia. Oncogenesis.

\section{INTRODUCTION}

The infection by the human T cell lymphotropic virus type 1 (HTLV-1) may cause several lymphoproliferative disorders, such as adult $\mathrm{T}$ cell leukemia/lymphoma (ATLL), one of the classic presentations of this infection. Its relationship, however, with other types of cancer is controversial and described in the literature by case reports or small case series. Matsuzaki et al. ${ }^{1}$, in 1990, described for the first time in the literature the association of non-ATLL neoplasia and HTLV-1 infection, a small cells type of lung cancer (SCLC) in Japan.

Lung cancer is the most frequent malignant tumor and has the highest mortality among all neoplasias. In 2012, 1.8 million new cases of lung cancer were diagnosed worldwide and 1.59 million deaths were recorded ${ }^{2}$. This cancer is classified into SCLC, the same described by Matsuzaki et al. ${ }^{1}$ and is our patient's type of cancer, with an overall 5-year survival rate of $6 \%$ and non-SCLC, with rates from 14 to $17 \%{ }^{3}$.

Several oncogenic factors are related to the tumorigenic process, involved in the dysregulation of apoptosis, leading to uncontrolled cell proliferation and angiogenesis, in addition to chronic inflammatory and infectious states ${ }^{3}$. Risk factors for its development are cigarette smoking, exposure to high air pollution environments, exposure to radiation, genetic predisposition, among others ${ }^{2}$. As the patient described in our case was a smoker, this is a confounding factor in the etiology of his lung cancer.

\section{CASE PRESENTATION}

A male patient, 60 years old, a previous drug user and cigarette smoker, was evaluated for the first time at the HTLV clinic in October 2017, when the 
HTLV-1 infection was confirmed, but he was aymptomatic at that time. The magnetic resonance imaging (MRI) of the thoracic spine showed a diffuse spinal atrophy with widening of the central canal, despite the absence of symptoms, and evidencing a myelopathy on the neurological examination, with a positive Babinski's sign on the right side. In March 2018, he was re-evaluated and had developed some weakness of the left lower limb accompanied by urinary incontinence. The neurologic examination revealed a proximal muscle weakness, grade 4 in the lower limbs, with spasticity and evident pyramidal signs, tetra hyperreflexia and presence of the Babinski sign. The HTLV-1 proviral load (PVL) was 47 copies/ $\mathrm{mL}$ and the T-cell proliferation (LPA) test was $1,148 \mathrm{cpm}$. At that time, he underwent a lumbar puncture to collect the cerebrospinal fluid (CSF), that showed 20 cells $/ \mathrm{mm}^{3}$ ( $85 \%$ lymphocytes and $15 \%$ monocytes), protein 47 $\mathrm{mg} / \mathrm{dL}$, glucose $37 \mathrm{mg} / \mathrm{dL}$, lactic acid $17 \mathrm{mg} / \mathrm{dL}$, and a negative oncological cytology. These conditions evolved over a time period of four months leading to dyspnea, dry cough and weight loss. In July 2018, the weakness of his lower limbs got worse as the urinary incontinence. He was undernourished, had mild dry cough and dyspnea. He was sent to the emergency department of the hospital and a chest X-ray (Figure 1) showed opacity of the left hemithorax and a deviation of the trachea. The chest tomography showed an image suggestive of pulmonary neoplasia and the anatomopathological exams (Figure 2) and immunohistochemistry (Figure 3 ) of the pulmonary lesion confirmed the presence of small cells lung epidermoid carcinoma. He progressed rapidly to death after one month after hospital admission due to respiratory failure. There was no specific treatment, only palliative care measures to minimize his suffering.

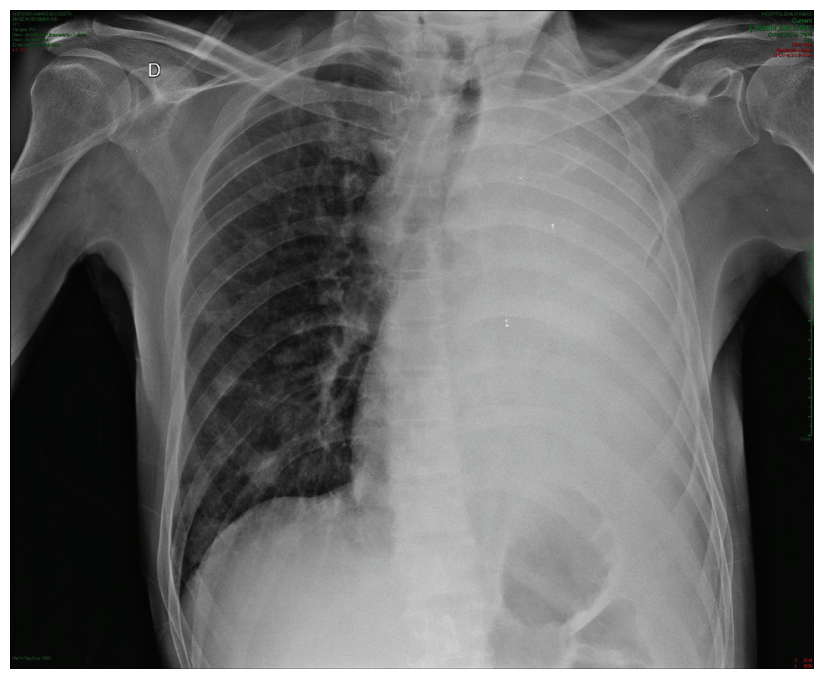

Figure 1 - Chest X Ray: opacity of the left hemithorax, with tracheal deviation.

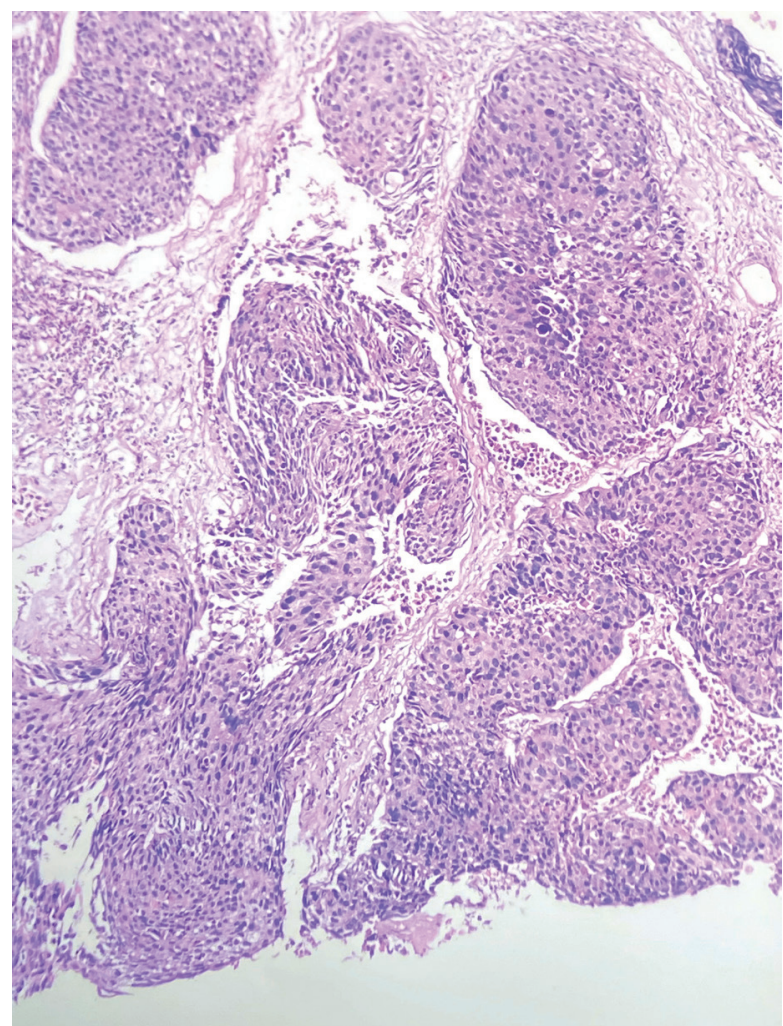

Figure 2 - Microscopic appearance of the lung tumour cells stained by Hematoxylin-eosin. Islands of large polygonal malignant squamous cells (x100 magnification).

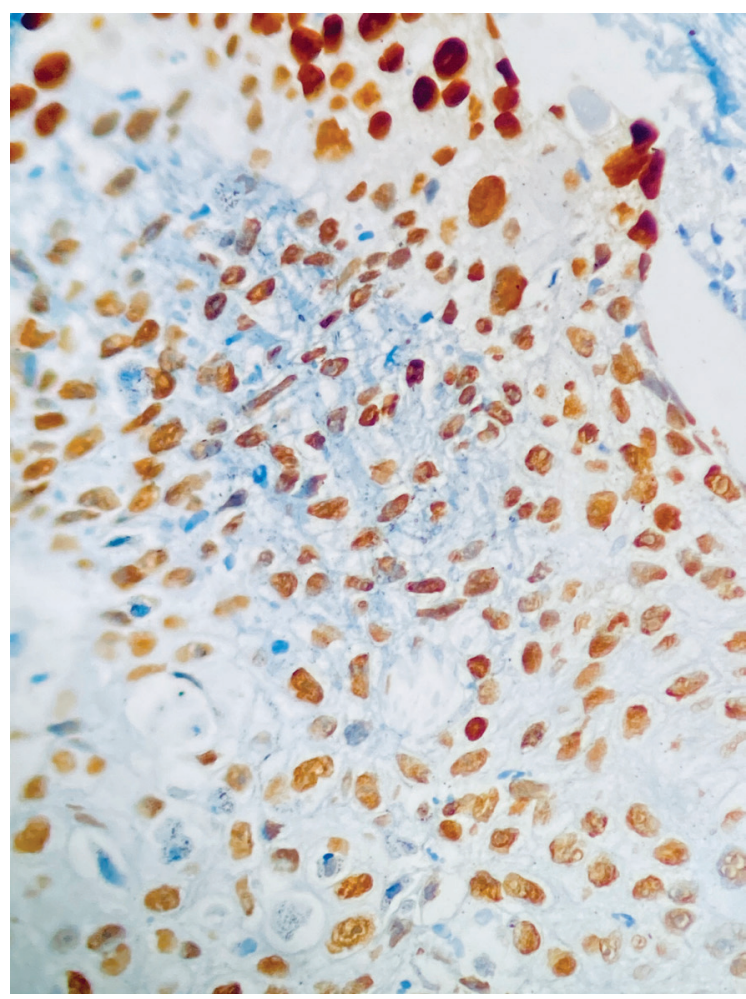

Figure 3 - A complementary immunohistochemistry exam showing nuclear positivity for the $\mathrm{P} 63$ protein that can differently stain Small Cells Lung Epidermoid Carcinoma (x 400 magnification). 


\section{DISCUSSION}

In 1990, Matsuzaki et al. ${ }^{1}$ described a 58 -year-old man with SCLC and a monoclonal integration of HTLV1 proviruses within DNA from the cancer cells was demonstrated. Besides that, the serum of this patient contained high levels of interleukin-2 receptors (IL2-R), and it was demonstrated that the SCLC cells from this patient were also positive for IL2-R. It is known that these receptors are expressed only on lymphoid cells ${ }^{4-6}$, so the author concluded that it is possible that HTLV-1 had induced the expression of IL2-R on the surface of SCLC cells, that are non-hematopoietic malignant cells. As described by Inoue $e t ~ a l .{ }^{7}$ in 1986 , a viral product encoded by the $\mathrm{pX}$ sequence of HTLV-1, called p4Ox, can induce the IL2-R gene expression on T-cells.

In addition, still on this type of neoplasia, Nomori et al. ${ }^{8}$ studied serum anti-HTLV-1 antibodies among 212 lung cancer patients without symptoms of HTLV-1 infection and found eight (4\%) positive cases: six were bronchioloalveolar carcinomas and two were adenocarcinomas with a bronchiolo-alveolar carcinoma component.

Asou et al. ${ }^{9}$, in 1986, observed five cases of neoplasia among 18 patients with a smoldering type of ATLL, such as cancer of the vagina, skin, stomach, and liver, and Kozuru et al. ${ }^{10}$ showed an increased risk of neoplasia (lung, uterine cervix, uterine corpus, breast, pharynx, esophagus, salivary glandand brain) in patients with ATLL, their mothers and siblings, in comparison with HTLV1-seronegative non-Hodgkin's lymphoma (NHL) patients, their siblings and their mothers.

Regarding the gynecological cancer, Miyazaki et al. ${ }^{11}$ reported that in women with cervical or vaginal carcinoma, the rate of tumor recurrence was significantly higher in those with HTLV1-positive serology. Oncogenic mechanisms that can be related to HTLV-1 influence the prognosis of these patients. Later, in 1995 in Jamaica, Strickler et al. ${ }^{12}$ found that in patients with cervical intraepithelial neoplasia grade 3 (CIN III) or invasive cancer of the uterine cervix, the seroprevalence of HTLV-1 was greater than among controls with low grade neoplasia or a non-characteristic abnormality with benign cervical pathology.

Despite these data, Hirata et al. ${ }^{13}$ analyzed 699 patients with cancer aged 50 years and older, diagnosed between 1991 and 2004 in Japan, and 1,365 controls without cancer. The prevalence of HTLV-1 infection in gastric cancer patients was significantly lower than in control patients without any neoplasia ${ }^{13}$. They have also found that the prevalences of HTLV-1 infection in patients infected by Helicobacter pylori (H. pylori) and controls without gastroduodenal disease were different, of $9.3 \%$ and $17.8 \%$, respectively. Data reporting HTLV-1 and this bacterium have also been also described by Isomoto $\mathrm{et} \mathrm{al.}{ }^{14}$, who found a lower prevalence of $H$. pylori in individuals with HTLV-1 infection in comparison with non-infected-HTLV-1 patients, and HTLV-1 infection reductions when patients were at risk of $H$. pylori infection and proliferation, reducing the risk of gastric cancer.

H. pylori is a known risk factor for gastric cancer and there are some evidences, described in these studies, that HTLV-1 modulates the immune response against $H$. pylori, therefore, reducing the risk of the latter ${ }^{15}$. On the contrary, Hirata et al. ${ }^{13}$ concluded that the HTLV-1 infection was not associated with an increased or reduced risk of other non-gastric cancers. This was corroborated by the study of Arisawa $\mathrm{et} \mathrm{al.} .^{16}$, who found no increment in the overall risk of developing other non-ATLL neoplasias, but a reduction in the risk of gastric cancer in patients with HTLV-1 infections. Tahaei et al. ${ }^{17}$ studied the relationship between gastric cancer and HTLV-1 infection in Iran, and the same result was found, with a lower prevalence of HTLV-1 infections among patients with gastric cancer.

Arisawa et al. ${ }^{18}$ evaluated the risk of cancer in HTLV1infected individuals over a period of 15.4 years and showed no association with an increased risk of developing cancer, excluding ATLL. However, the risk of liver cancer, hepatocellular carcinoma (HCC) in $86 \%$ of cases, was 2.1fold higher among HTLV-1 carriers than in non-carriers ${ }^{18}$. Firstly, this can be explained by the high rates of co-infection of HTLV-1 and HCV, due to the same route of infection, that is sexual or vertical transmission from mothers to their fetuses; or via contaminated organic fluids. Subsequent interactions between HCV and HTLV-1 are possible and the synergistic effect of these co-infections was evaluated in a study performed in Miyazaki city in Japan ${ }^{19}$.

Stuver et $a l .{ }^{20}$ have also assessed the relationship between liver cancer and HTLV-1. Between 1984 and 1993, there were 10 deaths from liver cancer, and five of them had anti-HTLV-1 antibodies. However, this co-infection does not appear to have impacted the increased risk of mortality due to liver cancer associated with the presence of anti-HCV antibodies.

Hirata et al..$^{21}$ evaluated clinical and pathological factors in breast cancer patients and their relationship with HTLV-1 infection. There was no clinical or pathological aspect in this cancer related to HTLV-1, including the disease-free time and total survival, unless the patients infected with HTLV-1 were older.

Several studies demonstrated the relationship of viral proteins that can induce the oncogenesis. In respect to ATLL, the transformation of normal $\mathrm{T}$ lymphocytes into infected $\mathrm{T}$ cells is made by an oncoprotein called Tax, 
encoded by HTLV $-1^{22}$. The infected T cells are subjected to genomic instability caused by the Tax-mediated inhibition of cellular DNA repair pathways and increased mutations in the cell genome ${ }^{23}$. Regarding tumors in humans, more than half of them have a mutation in the $\mathrm{p} 53$ protein, whose gene, the TP53, is located on chromosome $17 \mathrm{p} 13.1^{24}$. This is a tumor suppressor protein that induces cell death by means of apoptosis in cells that have undergone an oncogenic stress $^{25}$. Thus, the progression to malignancy depends on this loss of the p53gene function ${ }^{25}$.

Zane et $a l .{ }^{22}$ carried out a study with genetically modified mice to demonstrate that the relationship between the Tax protein and the p53 gene function would be inactivated by Tax. It has been shown that inactivation of the p53 gene by Tax occurs, but it is less significant than the inactivation that takes place through genetic mutation. It was also reported that the wild-type $\mathrm{p} 53$-induced phosphatase 1 (Wip1) contributes to Tax in this inhibition ${ }^{22}$.

Wip1 is a human protein phosphatase discovered in 1997 by Fiscella $e t ~ a l .{ }^{26}$ that is amplified and overexpressed in several human cancers. This protein, in a p53- gene dependent manner, might contribute to the growth suppression induced in response to DNA damage. In addition to the proteins already mentioned, in 2002 the HTLV-1 bZIP factor (HBZ) was identified, a novel basic leucine zipper factor. HBZ is consistently expressed in all ATL cases, unlike Tax, whose expression may be lost during the course of the infection $^{27}$. HBZ also plays an essential role in oncogenesis, by mechanisms not yet well known, that contribute to the development and continued growth of cancer ${ }^{28}$.

\section{CONCLUSION}

The correlation between HTLV-1 infection and other cancers than ATLL is still controversial in the literature, especially due to the small amount of published studies on the subject. We described here the case of a patient with HTLV-1 infection and a lung cancer type that coincides with the first description in the literature of a non-ATLL cancer associated with HTLV-1. Both, the clinical evolution of lung cancer and the HAM progressed rapidly, in less than one year, which may indicate the interplay of immunological and genetic factors of these two conditions. Further and broader studies are needed to elucidate this association, within a systematic clinical classification perspective that can encompass the full spectrum of primary and secondary complications associated with HTLV-1 infection.

\section{ACKNOWLEDGMENTS}

We thank our patient and his family for trusting us during follow-up care and during the preparation of this article.

\section{FUNDING}

Fapesp, grant N ${ }^{\circ}$ 2014/22827-7, Fundação Faculdade de Medicina and CNPq (grant to JC No 301275/2019-0).

\section{REFERENCES}

1. Matsuzaki H, Asou N, Kawaguchi Y, Hata H, Yoshinaga T, Kinuwaki E, et al. Human T-cell leukemia virus type 1 associated with small cell lung cancer. Cancer. 1990;66:1763-8.

2. Mao Y, Yang D, He J, Krasna MJ. Epidemiology of lung cancer. Surg Oncol Clin N Am. 2016;25:439-45.

3. Gomes M, Teixeira AL, Coelho A, Araújo A, Medeiros R. The role of inflammation in lung cancer. Adv Exp Med Biol. 2014;816:1-23.

4. Uchiyama T, Broder S, Waldmann TA. A monoclonal antibody (anti-Tac) reactive with activated and functionally mature human T cells. I. Production of anti-Tac monoclonal antibody and distribution of Tac (+) cells. J Immunol. 1981;126:1393-7.

5. Abo T, Miller CA, Balch CM, Cooper MD. Interleukin 2 receptor expression by activated HNK-1+ granular lymphocytes: a requirement for their proliferation. J Immunol. 1983;131:1822-6

6. Muraguchi A, Kehrl JH, Longo DL, Volkman DJ, Smith KA, Fauci AS. Interleukin 2 receptors on human B cells. Implications for the role of interleukin 2 in human B cell function. J Exp Med. 1985;161:181-97.

7. Inoue J, Seiki M, Taniguchi T, Tsuru S, Yoshida M. Induction of interleukin 2 receptor gene expression by $\mathrm{p} 40 \mathrm{x}$ encoded by human T-cell leukemia virus type 1. EMBO J. 1986;5:2883-8.

8. Nomori H, Mori T, Iyama K, Okamoto T, Kamakura M. Risk of bronchioloalveolar carcinoma in patients with human T-cell lymphotropic virus type 1 (HTLV-I): case-control study results. Ann Thorac Cardiovasc Surg. 2011;17:19-23

9. Asou N, Kumagai T, Uekihara S, Ishii M, Sato M, Sakai K, et al. HTLV-I seroprevalence in patients with malignancy. Cancer. 1986;58:903-7

10. Kozuru M, Uike N, Muta K, Goto T, Suehiro Y, Nagano M. High occurrence of primary malignant neoplasms in patients with adult T-cell leukemia/lymphoma, their siblings, and their mothers. Cancer. 1996;78:1119-24.

11. Miyazaki K, Yamaguchi K, Tohya T, Ohba T, Takatsuki K, Okamura H. Human T-cell leukemia virus type I infection as an oncogenic and prognostic risk factor in cervical and vaginal carcinoma. Obstet Gynecol. 1991;77:107-10.

12. Strickler HD, Rattray C, Escoffery C, Manns A, Schiffman $\mathrm{MH}$, Brown C, et al. Human T-cell lymphotropic virus type I and severe neoplasia of the cervix in Jamaica. Int J Cancer. 1995;61:23-6 
13. Hirata T, Nakamoto M, Nakamura M, Kinjo N, Hokama A, Kinjo $\mathrm{F}$, et al. Low prevalence of human $\mathrm{T}$ cell lymphotropic virus type 1 infection in patients with gastric cancer. J Gastroenterol Hepatol. 2007;22:2238-41.

14. Isomoto H, Mizuta Y, Fukushima K, Takeshima F, Miyazaki M, Murase K, et al Low prevalence of Helicobacter pylori in individuals with HTLV-I infection. Eur J Gastroenterol Hepatol. 1999;11:497-502.

15. Matsumoto S, Yamasaki K, Tsuji K, Shirahama S. Human $\mathrm{T}$ lymphotropic virus type 1 infection and gastric cancer development in Japan. J Infect Dis. 2008;198:10-5.

16. Arisawa K, Sobue T, Yoshimi I, Soda M, Shirahama S, Doi H, et al. Human T-lymphotropic virus type-I infection, survival and cancer risk in southwestern Japan: a prospective cohort study. Cancer Causes Control. 2003;14:889-96.

17. Tahaei SM, Mohebbi SR, Fatemi SR, Mohammadi P, Malek FN, Azimzadeh P, et al. Low frequency of human T-cell lymphotropic virus 1 antibodies in Iranian gastric cancer patients in comparison to controls. Asian Pac J Cancer Prev. 2011;12:2447-50.

18. Arisawa K, Soda M, Akahoshi M, Fujiwara S, Uemura H, Hiyoshi $\mathrm{M}$, et al. Human T-cell lymphotropic virus type-1 infection and risk of cancer: 15.4 year longitudinal study among atomic bomb survivors in Nagasaki, Japan. Cancer Sci. 2006;97:535-9.

19. Boschi-Pinto C, Stuver S, Okayama A, Trichopoulos D, Orav EJ, Tsubouchi $\mathrm{H}$, et al. A follow-up study of morbidity and mortality associated with hepatitis $\mathrm{C}$ virus infection and its interaction with human T lymphotropic virus type I in Miyazaki, Japan. J Infect Dis. 2000;181:35-41.
20. Stuver SO, Okayama A, Tachibana N, Tsubouchi H, Mueller NE, Tabor E. HCV infection and liver cancer mortality in a Japanese population with HTLV-I. Int J Cancer. 1996;67:35-7.

21. Hirata M, Shinden Y, Nagata A, Nomoto Y, Saho H, Nakajo A, et al. Clinical features of breast cancer patients with human T-cell lymphotropic virus type-1 infection. Asian Pac J Cancer Prev. 2019;20:1909-12.

22. Zane L, Yasunaga J, Mitagami Y, Yedavalli V, Tang SW, Chen CY, et al. Wip1 and p53 contribute to HTLV-1 Tax-induced tumorigenesis. Retrovirology. 2012;9:114.

23. Zhang LL, Wei JY, Wang L, Huang SL, Chen JL. Human T-cell lymphotropic virus type 1 and its oncogenesis. Acta Pharmacol Sin. 2017;38:1093-103.

24. Freed-Pastor WA, Prives C. Mutant p53: one name, many proteins. Genes Dev. 2012;26:1268-86.

25. Vousden KH, Lu X. Live or let die: the cell's response to p53. Nat Rev Cancer. 2002;2:594-604.

26. Fiscella M, Zhang H, Fan S, Sakaguchi K, Shen S, Mercer WE, et al. Wip1, a novel human protein phosphatase that is induced in response to ionizing radiation in a p53-dependent manner. Proc Natl Acad Sci U S A. 1997;94:6048-53.

27. Takeda S, Maeda M, Morikawa S, Taniguchi Y, Yasunaga J, Nosaka K, et al. Genetic and epigenetic inactivation of tax gene in adult T-cell leukemia cells. Int J Cancer. 2004;109:559-67 .

28. Zhao T. The role of HBZ in HTLV-1-induced oncogenesis. Viruses. 2016;8:34 